\title{
Recent Advances of Integrative Bio-Omics Technologies to Improve Type 1 Diabetes (T1D) Care
}

\author{
Nisha Karwal ${ }^{1}$, Megan Rodrigues ${ }^{1}$, David D. Williams ${ }^{1}$, Ryan J. McDonough ${ }^{2}$ and Diana Ferro ${ }^{2, *(\mathbb{D}}$ \\ 1 Children's Mercy Research Institute, Hospital and Clinics, Kansas City, MO 64108, USA; \\ nkarwal@cmh.edu (N.K.); mrodrigues@cmh.edu (M.R.); ddwilliams@cmh.edu (D.D.W.) \\ 2 Department of Pediatrics, University of Missouri Kansas City, Kansas City, MO 64108, USA; \\ rjmcdonough@cmh.edu \\ * Correspondence: dferro@cmh.edu; Tel.: +1-(816)-7317242
}

Citation: Karwal, N.; Rodrigues, M.; Williams, D.D.; McDonough, R.J.;

Ferro, D. Recent Advances of Integrative Bio-Omics Technologies to Improve Type 1 Diabetes (T1D) Care. Appl. Sci. 2021, 11, 11602. https:// doi.org/10.3390/app112411602

Academic Editors: Oleg Karaduta and Mari K. Davidson

Received: 11 November 2021

Accepted: 2 December 2021

Published: 7 December 2021

Publisher's Note: MDPI stays neutral with regard to jurisdictional claims in published maps and institutional affiliations.

Copyright: (c) 2021 by the authors. Licensee MDPI, Basel, Switzerland. This article is an open access article distributed under the terms and conditions of the Creative Commons Attribution (CC BY) license (https:/ / creativecommons.org/licenses/by/ $4.0 /)$.

\begin{abstract}
Type 1 diabetes (T1D) is a complex autoimmune disease that currently cannot be cured, only managed. Optimal treatment the of T1D symptoms, requires a multidisciplinary care team, including endocrinologists, educators, primary care providers, health care specialists, genetic counselors, and data scientists. This review summarizes how an integrative approach to T1D drives innovation and quality improvements in health care. Specifically, we highlight how "-omics" technologies facilitate the understanding of different aspects of the disease, including prevention, pathogenesis, diagnostics, and treatment. Furthermore, we explore how biological data can be combined with personal and electronic health records to tailor medical interventions to the individual's biology and lifestyle. We conclude that truly personalized medicine will not be limited to one data source but will emerge from the integration of multiple sources and disciplines that together will support individuals with T1D in their everyday life.
\end{abstract}

Keywords: genomics; diabetes; big data; T1D

\section{Introduction}

Type 1 diabetes (T1D) is a complex T-cell mediated autoimmune disease defined by the destruction of insulin-secreting pancreatic beta cells [1,2]. Untreated T1D produces profound hyperglycemia, warranting a lifetime therapy of exogenous insulin administration [3,4]. Clinical advancements include a broad range of therapeutic options, including different forms of insulin administration methods (i.e., insulin pump, multiple daily injections (MDI), sensor-augmented pumping, and advanced hybrid closed loop pump systems) [3-5]. The success of such targeted treatment options is dependent on a detailed understanding of the patient's physiology, genetics, and environment $[1,6]$. This holistic exploration of individuals' "-omics" has the potential to identify novel biomarkers that play a role in the establishment of T1D and to inform the design of new therapeutic drugs [7]. Molecular analyses can provide deeper insights into T1D disease processes, although associations among genetic mutations, biomarkers, environmental exposures, and disease states are still underexamined [7]. This review examines current "-omics" literature related to T1D with a focus on prevention, pathogenesis, genetic markers, diagnostic methods, treatment, device and personal health records, complications, and the role of the environment.

\section{Prevention}

It is important to understand the pathogenesis of T1D to prevent complications. This includes the characterization of genetic risk factors, physiologic alterations, and environmental triggers [8]. For example, multiple loci on chromosomes 8 and 12, show a strong risk associated with age, in individuals with T1D. Indeed, while single associations have been made between specific genes, biomarkers and environmental exposures, the interplay of these different variables has yet to be explored [7]. Furthermore, information 
on associations among different disease states is currently limited. By using aggregated "-omics" data, relationships between different genetic predispositions and environmental influences on T1D can not only be explored but may help to identify at-risk individuals requiring early intervention.

An example of a successful approach, that uncovered the interplay between individual genetic and environment, is The Environmental Determinants of Diabetes in the Young (TEDDY) study, for which researchers measured a wide variety of environmental triggers in children who were at high genetic risk for T1D [8]. There is an ongoing opportunity to explore connections between seemingly disconnected environmental variables, by using the resulting database of exposures and metabolic profiles. Investigators linked a metabolic signature and subsequent alteration in specific physiologic processes (i.e., upregulation of energy-producing pathways, downregulation of lipogenic processes) that preceded [8,9]. In the TEDDY study, researchers were able to establish a timeline from when these physiological processes occur to complete disease onset, preceding the development of T1D-related autoimmunity by up to 12 months [9].

Further commonalities can be found in the pathogenesis of T1D between different disease states. For example, investigators identified that the pentose phosphate pathway and pyrimidine metabolism were altered in children with islet autoimmunity born by Cesarean section [10]. The profile of these transcriptomic differences showed similarities with gene expression alterations during the activation of CD4+ T lymphocytes and other immune system factors like those found in islet autoimmunity in individuals with T1D [11]. The investigators concluded that the transcriptomic differences found within an individual delivered by Cesarean section may lead to the potential development of islet autoimmunity and T1D [10].

Aggregation of available "-omics" data and investigation of possible associations may allow profiles of at-risk individuals to be constructed [12]. The inclusion of other environmental factors and disease processes can create a more comprehensive assessment of T1D pathogenesis [13]. Recent studies uncovered correlations between immune insults, such as virus infection (i.e., enterovirus), with the onset of immune mechanisms imitating beta-cell antigens, and therefore, demonstrated a molecular mechanism underpinning the development of T1D as a consequence of exogenous exposure [14]. Psychological factors, such as physiological responses to generalized stress, are known to affect T1D disease onset and management [15-17]. It has been demonstrated that negative influences in the individual's environment, such as the presence of family conflict, compromise metabolic control, and therefore increase the risk for T1D-related complications [18]. Importantly, resolving the stressful family conflict does not prevent or delay disease onset, but can improve treatment effectiveness and prevent long-term complications, thereby lowering direct medical costs $[19,20]$.

\section{Pathogenesis and Biomarkers}

Modern technologies and advancements in medicine have progressed past the "one size fits all" approach in therapeutic options. One important tool in this context is the molecular analysis of gene variants to identify genes involved in the pathogenesis of T1D [7,21-23]. The products of these genes often referred to as biomarkers, may provide information related to better disease treatment and management. Especially studies that included micro-RNA expression analysis have aided in the understanding of the pathogenesis of T1D.

New-onset T1D has been associated with the overexpression of the gene Forkhead Box O3 (FOXO3) and a low expression of a pancreas-specific microRNA, called miR$375[24,25]$. FOXO3 is a transcription factor involved in the development and differentiation of regulatory T-cells. High expression levels of FOXO3, along with the ongoing islet autoimmune destruction, in new-onset T1D individuals may explain the exhaustion and dysfunction seen in their regulatory T-cell populations [26-28]. miR-375 has been shown to target insulin-induced gene 2 (INSIG2), which regulates insulin secretion and beta-cell 
mass [25]. The gene expression levels of miR375 and FOXO3 could serve as biomarkers for T1D and should be further explored to possibly prevent the progression of new-onset diagnosis of the disease.

Additionally, other genes and microRNAs have been identified as showing signs of differential expression in the development of T1D. Syreeni et al. identified two chromosomal regions associated with T1D diagnosis age, which are found in the chromosomal location Chr17q12 and near the gene P.H.D. finger protein 20 like 1 (phf20l1) on chromosome 8 [12]. In individuals with T1D miR-148a and miR-181a are found to be elevated in the blood, and miR-21 and miR-155 are elevated in urine [29]. These genes and microRNAs may prove to be useful biomarkers for the prediction of T1D development and warrant further investigation.

Metabolomic data offers new insights into T1D-related autoimmunity by assessing the role of gene regulation and dietary exposure in the development of T1D. Gene expressionassociated dysregulation of vitamins in circulation were assessed in the TEDDY study, yielding results indicative of lower plasma Vitamin C and D levels at infancy in HLADR3/DR4 children [9]. In a study by Kraus et al., in vitro treatment with $1,25(\mathrm{O} . \mathrm{H} .)_{2} \mathrm{D}_{3}$ reduced proinflammatory cytokines, including interleukin 6 (IL-6), chemokine 2 (CCL-2), interleukin $23 \mathrm{~A}$ (IL-23A), and interleukin 15 (IL-15). Furthermore, the treatment also increased levels of anti-inflammatory cytokines (such as interleukin 10 (IL-10)) and affected the programmed death-ligand 1 gene (PD-L1) in individuals with T1D [30,31]. Animal studies demonstrated that upregulation of PD-L1 expression can be preventive against T1D progression as it leads to the persistence of neo-islet supporting insulin production [32]. By assessing gene regulation as well as nutrient intake, metabolomic data provide the most practical information in creating risk profiles for the development of autoimmune diseases, such as T1D. In fact, researchers have successfully used metabolomic data to identify biomarkers predicting the genetic susceptibility to diet-induced beta-cell failure [31]. Specifically, in individuals with the rare genetic syndrome called Mutant INS-gene-induced Diabetes of Youth (MIDY), a mutation in the proinsulin-R(B22)E and $Q$ causes misfolding of the proinsulin protein in the endoplasmic reticulum. This triggers rapid insulin deficiencies and results in glucose intolerance upon exposure to a high-fat diet [33-35]. Interestingly, molecular studies in animal models propose that evolution is maintaining islet cell heterogeneity and that mutations affecting protein-folding might serve as important predictors for diabetes outcomes, especially hypoglycemia [33].

Lastly, "-omics" data can also be used to find shared biomarkers and modes of pathogenesis between T1D and other T-cell mediated diseases. Using transcriptome and interactome analyses, Safari-Alighiarloo et al. identified several cytokines, such as interleukin 23-A (IL-23A), interleukin 32 (IL-32), interleukin 34 (IL-34), and interleukin 37 (IL-37), that are differentially expressed in T1D and multiple sclerosis (MS) [36,37]. Gene ontology analysis is commonly used to generate protein-protein interaction networks and identify common pharmacologic targets that can facilitate therapeutic innovations (i.e., through drug repurposing) $[38,39]$. Over the years, researchers identified numerous shared biological processes affected in individuals with T1D and MS. Those include pathways associated with the proteasome, spliceosome, immune responses, apoptosis, cellular communication/signaling transduction mechanism, interaction with the environment, and activity of intercellular mediators [36]. The molecular comparison of the molecular processes underlying T-cell mediated diseases offers a framework to identify potential therapeutic targets for either disease, lowering the overall development costs and timelines. Bioinformatic tools, such as the integrated Complex Traits Networks 2 (iCTNet2) provide the foundation for the comparison of comprehensive diseases-specific "-omics" databases, also called "diseasomes", and support drug repurposing strategies [40,41].

\section{Diagnostic Methods}

Traditional diagnostic methods for T1D disregard differences in physiology and may possibly lead to delayed diagnoses. The current diagnostic methodology commonly 
includes the fasting blood glucose test, oral glucose tolerance test, random blood-glucose test, glycated hemoglobin test (HbA1c).

Endocrine clinics might also request to test $C$-peptide antibodies, insulin antibodies (IAA), insulin-associated-2antibodis (IA-2A), zing-transporter 8 (ZnT8Ab), islet cell cytoplasmic autoantibodies (ICA), and Glutamic Acid Decarboxylase Autoantibodies (GADA or Anti-GAD). There are two main issues associated with the current methodology of diagnosis. First, diagnosis is often delayed until symptoms develop, which is already too late in the disease to preserve beta-cell function using pharmacologic treatment, such as [42]. Second, the tests insufficiently take into account physiological differences across gender and race. Stratified population studies demonstrated that the use of genomic information and other biomarkers may augment traditional methods for a more comprehensive, accurate, and more rapid diagnosis [26,43]. The identification of specific biomarkers for certain demographic groups may aid diagnosis methods for T1D, including age, gender, and race. A study on 711 children, newly diagnosed with T1D, highlighted how the islet autoantibody type is strongly associated with demographics [44]. Additionally, Gan et al. assessed the quantity of specific biomarkers related to each demographic group through proteomic analysis [7]. The most common traditional biomarkers are islet autoantibodies including IA-2A, GAD, ZnT8Ab autoantibodies [45]. The later-age onset of T1D is related to characteristic levels of GADA, thyroid peroxidase (TPOA), and gastric parietal cell antibodies (PCA) in the individual. Females with T1D often have autoantibodies for GAD, TPO, PC, and transglutaminase (TGA). GADA are found more commonly in African Americans while TGA are more frequently found in Native Americans with T1D [42]. These gender and race-associated differences should be leveraged to improve diagnostic methods for T1D. Gan et al. also analyzed metabolomic data of T1D individuals for potentially characteristic expression profiles [7]. Advanced glycation end-products (AGE) were found to be deposited in the skin of individuals with T1D [46]. AGE can be measured using skin autofluorescence, which might serve as a non-invasive method to diagnose T1D [47]. Lastly, autoimmune diseases are often associated with other immune alterations, such as hypothyroidism and/or celiac disease. Therefore, "-omics" technology can offer an opportunity to identify commonalities in genetic variability that can be targeted with specialized therapeutics [48]. Further investigation is necessary to better define endotypes and identify novel biomarkers that can be used by care providers to improve detection methods for T1D.

\section{Treatment of Diabetes}

Novel biomarkers and metabolic profiles can be leveraged to identify drug targets for the development of therapeutics, both for the treatment of T1D or more generally, the prevention of autoimmune disorders. In Shepherd et al., investigators identified a gene mutation that causes individuals to be misdiagnosed as having T1D [49]. These individuals carry a mutated allele of the gene hepatocyte nuclear factor-1 alpha (HNF1 $\alpha$ ), resulting in a monogenic form of diabetes, MODY3, which does not cause insulin dependency as found in most individuals with T1D. Differently than in regular T1D, sulphonylureas are more efficacious for MODY3 individuals when compared to insulin therapy and are the potentially better treatment option with a broader therapeutic window for this subpopulation [50]. This shows that accruing genomic information can alter the therapeutic outlook, even in diseases with a similar presentation, and can be used to create unique therapeutic approaches that will ultimately result in better outcomes for individuals [23].

Furthermore, as mentioned above, metagenomic studies and the technological advances in computational sciences, provide modern medicine with the opportunity to identify new drugs for the treatment of T1D and the repurposing of FDA-cleared compounds. In the Zhang et al. study, 992 proteins from previous proteomic and metabolomic studies were identified as potential drug targets [48]. These targets were cross-referenced with drug libraries to identify nine drugs with the potential to treat T1D $[29,51]$. In repurposing existing medications, the investigators also explored how these targets were 
similar to others found in diseases such as Alzheimer's Disease, further emphasizing the value of large-scale "-omics" data [37,52]. The ability to find associations between seemingly independent factors provides a more comprehensive understanding of disease states and allows for innovative approaches to therapeutics. Recent evidence points to shared etiological features between T1D and type 2 diabetes (T2D). Although, the two diseases have a very different clinical presentation and pathophysiology, Genome-Wide Association Studies (GWAS) have uncovered common loci, including the transcription factor 7-like 2 loci (TCF7L2). T1D and T2D disproportionally affect adults and youth, respectively, with T2D being more common in adults. However, it has been identified that $\sim 15 \%$ of common genes between T1D and T2D encode for proteins targeted by FDA-approved drugs [53,54]. Some of those drugs cause diabetes or diabetes-like symptoms themselves, including hypoglycemia (i.e., streptozotocin, pembrolizumab, nivolumab, and doxorubicin). However, numerous compounds have been successfully used for the treatment of either form of diabetes and could be repurposed for the treatment of the other form. For example, disulfiram, pirfenidone, and tretinoin have recently been successfully used to normalize glycemic dysregulation and treat complications in individuals with T1D and T2D. Another large-scale study performed on 61,427 participants with T1D, used fine-mapping, trans-ancestral and genomic analysis to identify novel potential drug targets. Robertson and coworkers, highlighted at least 50 candidate target genes, however only 12 are currently investigated in clinical trials for autoimmune diseases (including $I L-6 R)$ [55]. To prioritize the most promising therapeutics, researchers use a combination of methods to predict the interaction between drugs and their targets in the context of biological and disease system-level networks. Molecular docking analysis highlighted another group of FDA-approved compounds for their potential use as T1D therapeutics, including melatonin, resveratrol, eugenol, lapatinib, geldanamycin, and azathioprine. The analysis selected the drugs due to their activity against products of genes, differentially expressed in beta-cells of individuals with T1D, including Estrogen Receptor 1 (ESRI), erb-b2 receptor tyrosine kinase 2 (ERBB2), Heat Shock Protein 90 Alpha Family Class B Member 1(HSP90AB1) and Rac Family Small GTPase 1 (RAC1). These genes have been shown to be involved in the deterioration of beta-cell functionality, impairment in glucose uptake, and protein folding, and therefore were proposed as clinical targets based on validation in animal models [56].

\section{Device and Personal Health Records}

Pharmacological treatment of T1D is necessary but is not the only therapeutic strategy used in clinics to empower individuals in managing their blood glucose variation and prevent associated complications [57]. Wearable therapeutic devices are common in the treatment of T1D and from continuous glucose monitors (CGM) to insulin pumps, broad data is available to analyze and establish patterns in the control and management of T1D. Investigators can evaluate behavioral factors to assess how variations in personal management affect glycemic outcomes. Advanced Hybrid Closed Loop (AHCL) systems have been shown to be effective for $\mathrm{HbA} 1 \mathrm{c}$ reduction [3-5]. These devices allow individuals to learn about their personal differences, which can be further analyzed for improved disease control. In the Morton et al. study, investigators explored associations between meal size, insulin dose, glycemic variability, and sleep disturbances [58]. They found that smaller meals and smaller insulin dosages were associated with decreased glycemic variability and better outcomes. They also found that there was no association between interrupted sleep and glycemic outcomes. The authors conclude that even if using an insulin pump or CGM is not the individual's treatment of choice, the insight gained from analyzing device data can still be applied to other methods of management. Furthermore, analysis of device data can be used to predict adverse glycemic events and can prevent poor outcomes [59].

Daily fluctuations in blood glucose levels differ among individuals with T1D. Longitudinal blood glucose control can be assessed by $\mathrm{HbA} 1 \mathrm{c}$ measurements every 3-4 months or via calculating the CGM Time in Range (70-180 mg/dL). Personal health records involving 
diet, exercise, insulin compliance as well as other factors, can also be used to study whether to what degree individual behavior affects glycemic control [60]. Furthermore, levels of endogenous residual insulin production, as measured by stimulated c-peptide must be considered by care provides, since it is a contributing factor to glycemic control in new-onset individuals with T1D [61]. In fact, Rickels et al. reported that beta-cell responsiveness to hyperglycemia and alpha-cell responsiveness to hypoglycemia are observed only at high levels of residual c-peptide that likely contribute to glycemic control [62]. Clements et al. revealed that a glucometer-connected mobile app may increase an individual's engagement with other aspects of care, such as self-monitoring of blood glucose (SMBG) frequency. While data from personal health records can help outline trends and predict future adverse events for the individual, how to transition to algorithm creation and machine learning is still unclear. The quality of data used should be reliable and representative of the target population to ensure validity [63-66]. More research needs to be done to ascertain how and to what degree mobile devices can improve glycemic control in individuals with T1D [67].

\section{Complications of T1D}

Pharmacological treatment and engagement in self-monitoring improve diabetes outcomes, but currently does not account for genetic predisposition to develop long-term complications. "-Omics" studies, such as metabolomics and gene expression studies, may offer effective approaches to augment conventional treatment strategies and reduce the impact such complications.

Diabetic neuropathy and peripheral artery disease (PAD) are common complications of poor glucose control. Identifying genes related to an increased risk for these complications may provide a therapeutic target pathway. Aghanoori et al. identified genes related to diabetic neuropathy and offered an approach to restore nerve function [68]. Insulinlike Growth Factor (IGF-1) activates AMP-activated protein kinase (AMPK) to augment mitochondrial function and rebalance the neuronal metabolism of sensory neurons in individuals with T1D. Dorsal root ganglia of rats with streptozotocin-induced T1D were treated with IGF-1, which provided protection from neuropathy in the animal model and offers a promising approach to therapeutic options for individuals with diabetic neuropathy. Peripheral artery disease (PAD) is another common long-term complication of T1D, typically developing over a period of years due to repeated T1D-induced hypoxia in circulation. It is caused by occlusion of blood vessels and individuals with T1D are at higher risk to experience poor outcomes due to PAD. Peravali et al. analyzed the genome-wide mRNA transcriptome in a mouse model and found that hypoglycemia alters ischemiainduced gene expression [69]. The identified 443 differentially expressed genes are involved in the cell cycle, DNA replication, metabolic pathways, focal adhesion, regulation of actin cytoskeleton, and nucleotide excision repair in mice. Furthermore, a GWAS study provided evidence for the mechanism underpinning the complication in humans and identified two genomic regions strongly associated with PAD ( $\mathrm{rs} 116405693$ and coiled-coil serine-rich protein 1 (CCSER1)) confirming the genetic association between the long-term complication and T1D [70].

\section{Environment \& T1D}

Dennis et al. define the term "exposome" as the totality of environmental exposures throughout a lifetime. These include endogenous and exogenous factors that interact with the human body and biological processes [71]. Researchers classify exposures into three categories: internal exposures, arising from endogenous pathways; external exposures such as infections, diet, and substance use; and general external exposures that broadly include the geography and climate a person lives in, socioeconomic status, and the psychosocial environment [13]. Although the environment of a given individual is dynamic, studies using metabolomic data have shown associations with environmental factors such as the gut microbiome [72]. Additionally, Passero et al. found that environmental risk scores for oxidative stress were associated with cardiovascular phenotypes [71]. Whether this 
environmentally-induced oxidative stress correlates with endogenous oxidative stress in the metabolic process of blood glucose regulation in pre-diabetic individuals is unclear as of yet $[8,73]$. Environmental exposure to pollutants has been associated with a higher risk of developing oxidative stress-related pathogenesis including diabetes mellitus, cardiovascular diseases, and neurodegeneration. For example, more than 200 million persons worldwide are exposed to arsenic, which has been demonstrated to induce oxidative stress. This can lead to the death and dysfunction of beta-cells, thus weakening blood glucose control and increased insulin resistance in affected individuals [72]. Findings such as the above mentioned, demonstrate that biological processes should be considered as open systems exhibiting a complex interplay with their associated environment. Consequently, we need to consider the concept of etiological and systematic wholes in designing clinical studies of complex diseases [74].

\section{Discussion}

While the ideas presented in this review shed light on innovative methods to improve T1D care, the research to evaluate the importance of specific tests is still ongoing. For instance, studies that calculate the positive and negative likelihood ratio among the various biomarkers present in individuals with T1D must be performed to assess the usefulness of specific biomarkers in predicting T1D. With regards to the prevention of T1D, what if the decision to correct the pentose phosphate pathway and pyrimidine synthesis in C-section delivered babies creates far worse medical outcomes than T1D? An idiopathic disruption of metabolism could rather be considered harmful rather than helpful in such a case. In terms of the interconnectedness of the environment and T1D, the difficulty in attaining an accurate record of exposures remains high. The duration and intensity of exposure are difficult to quantify without continuous monitoring. But the question remains if continuous monitoring of all relevant exposures is realistic across an individual's lifetime.

This review highlights "-omics"-derived variables involved in the pathogenesis and prognosis of T1D. A comprehensive list of all factors related to the development of T1D would be beneficial for future physicians to provide optimal care for individuals. For example, a database containing all risk factors that contribute to the development of T1D correlated with age, risk assessment, and likelihood ratios would provide valuable information for physicians to proactively care for pre-T1D and T1D individuals. Such a data resource should include an interleukin panel describing presence-absence patterns and whether any mutations previously associated with increased risks were found in the individual's genome. The TCF7L2 gene and other relevant loci might provide insights into novel drug targets. Integration of "-omics" data in the individual's records could allow for the creation of novel algorithms aiding diagnosis, treatment, and management of T1D. However, it is important to keep in mind that algorithm-based tools are only as useful as the data used to construct them. The reliability and prevalence of the associations with T1D disease state must also be strong enough for an algorithm to be beneficial in this context.

Using the concepts in this review to generate accurate T1D data could contribute to the production of a diagnostic checklist for use in pediatric care aimed to prevent the development and/or progression of T1D. Detecting potential adverse events with accurate data paired with personal health record monitoring could offer a reliable use of predictive data. In fact, recent initiatives, such as the Rising T1De Alliance, have demonstrated that this information can be used to predict diabetes outcomes (i.e., glycemic control), analyze behavior (i.e., device disengagement), and provide rapid and precise treatment options in the form of personalized intervention that successfully decreases the risk for diabetes complications (i.e., remote patient monitoring) [75].

\section{Conclusions}

T1D is a chronic condition that requires continuous clinical oversight and individual management. Diagnosis is often made after the destruction of $70-80 \%$ of beta-cells [76]. A gap in understanding the onset precursors and origin of diabetes limits providers from 
making earlier diagnoses. This review of "-omics" technologies offer an informed examination of the genetic and environmental precursors to diabetes onset, establishment, and management. Furthermore, we highlight the role of the environment in the treatment of the disease as well as the untapped potential of using comprehensive data to build predictive algorithms to forecast negative outcomes and intervene proactively to support the individual with customized care. Importantly, we do not intend this review to be a comprehensive discussion of all the topics addressed therein, but instead, aim to stimulate discourse around exploring the use of integrative technologies to improve diabetes outcomes. Additionally, we chose to keep this review generalist in nature, as we seek to inspire the scientific community at large, independently of their background, to consider more of the various informative aspects of T1D while designing research studies or medical trials.

We believe that future technological advancements in cloud computing and the collaboration across worldwide online registries will eventually allow for integrative medical science to provide individuals with T1D true real-time personalized care.

Author Contributions: N.K., M.R. and D.F. developed the narrative and wrote the manuscript. D.D.W. contributed to the writing and participated in the revision process. R.J.M. aided in interpreting the clinical literature and provided support to the theoretical workflow. D.F. devised the project, proofed the outline, and oversaw the overall direction and planning. All authors have read and agreed to the published version of the manuscript.

Funding: The present study was funded by the Leona B. and Harry M. Helmsley Charitable Trust foundation [G-2017PG-T1D019 and 2008-04043].

Institutional Review Board Statement: Not applicable.

Informed Consent Statement: Not applicable.

Data Availability Statement: Not applicable.

Acknowledgments: The authors would like to thank Shelby Carrothers (Children's Mercy Hospital, Kansas City) for assisting with the writing of the first draft, Kevin Ferro (Stower's Institute for Medical Research, Kansas City) for the critical review of the final manuscript and Mark Clements (Children's Mercy Hospital, Kanas City) for his support and interest. We are grateful to all reviewers and editors for their helpful comments.

Conflicts of Interest: The authors declare no conflict of interest.

\section{References}

1. Miller, R.G.; McGurnaghan, S.J.; Onengut-Gumuscu, S.; Chen, W.M.; Colhoun, H.M.; Rich, S.S.; Orchard, T.J.; Costacou, T. Insulin Resistance-Associated Genetic Variants in Type 1 Diabetes. J. Diabetes Its Complicat. 2021, 35, 107842. [CrossRef] [PubMed]

2. Diagnosis and Classification of Diabetes Mellitus. Diabetes Care 2009, 32, S5-S10.

3. Nagel, K.E.; Dearth-Wesley, T.; Herman, A.N.; Smith, H.G.; Whitaker, R.C. Diabetes Distress and Glycaemic Control in Young Adults with Type 1 Diabetes: Associations by Use of Insulin Pumps and Continuous Glucose Monitors. Diabet. Med. 2021, 38, e14660. [CrossRef] [PubMed]

4. Hanas, R.; Lindgren, F.; Lindblad, B. A 2-Yr National Population Study of Pediatric Ketoacidosis in Sweden: Predisposing Conditions and Insulin Pump Use. Pediatric Diabetes 2009, 10, 33-37. [CrossRef] [PubMed]

5. Karges, B.; Schwandt, A.; Heidtmann, B.; Kordonouri, O.; Binder, E.; Schierloh, U.; Boettcher, C.; Kapellen, T.; Rosenbauer, J.; Holl, R.W. Association of Insulin Pump Therapy vs Insulin Injection Therapy with Severe Hypoglycemia, Ketoacidosis, and Glycemic Control among Children, Adolescents, and Young Adults with Type 1 Diabetes. JAMA-J. Am. Med Assoc. 2017, 318, 1358-1366. [CrossRef]

6. Kristensen, L.J.; Birkebaek, N.H.; Mose, A.H.; Jensen, M.B.; Thastum, M. Multi-Informant Path Models of the Influence of Psychosocial and Treatment-Related Variables on Adherence and Metabolic Control in Adolescents with Type 1 Diabetes Mellitus. PLoS ONE 2018, 13, e0204176. [CrossRef]

7. Gan, W.Z.; Ramachandran, V.; Lim, C.S.Y.; Koh, R.Y. Omics-Based Biomarkers in the Diagnosis of Diabetes. J. Basic Clin. Physiol. Pharmacol. 2020, 31, 1-21. [CrossRef]

8. Balzano-Nogueira, L.; Ramirez, R.; Zamkovaya, T.; Dailey, J.; Ardissone, A.N.; Chamala, S.; Serrano-Quílez, J.; Rubio, T.; Haller, M.J.; Concannon, P.; et al. Integrative Analyses of TEDDY Omics Data Reveal Lipid Metabolism Abnormalities, Increased Intracellular ROS and Heightened Inflammation Prior to Autoimmunity for Type 1 Diabetes. Genome Biol. 2021, 22, 39. [CrossRef] 
9. Li, Q.; Liu, X.; Yang, J.; Erlund, I.; Lernmark, Å.; Hagopian, W.; Rewers, M.; She, J.X.; Toppari, J.; Ziegler, A.G.; et al. Plasma Metabolome and Circulating Vitamins Stratified Onset Age of an Initial Islet Autoantibody and Progression to Type 1 Diabetes: The TEDDY Study. Diabetes 2021, 70, 282-292. [CrossRef]

10. Laimighofer, M.; Lickert, R.; Fuerst, R.; Theis, F.J.; Winkler, C.; Bonifacio, E.; Ziegler, A.G.; Krumsiek, J. Common Patterns of Gene Regulation Associated with Cesarean Section and the Development of Islet Autoimmunity-Indications of Immune Cell Activation. Sci. Rep. 2019, 9, 6250. [CrossRef]

11. Boldison, J.; Long, A.E.; Aitken, R.J.; Wilson, I.V.; Megson, C.; Hanna, S.J.; Wong, F.S.; Gillespie, K.M. Activated but Functionally Impaired Memory Tregs Are Expanded in Slow Progressors to Type 1 Diabetes. Diabetologia 2021, 1-13. [CrossRef]

12. Syreeni, A.; Sandholm, N.; Sidore, C.; Cucca, F.; Haukka, J.; Harjutsalo, V.; Groop, P.H. Genome-Wide Search for Genes Affecting the Age at Diagnosis of Type 1 Diabetes. J. Intern. Med. 2020, 289, 662-674. [CrossRef]

13. Passero, K.; Setia-Verma, S.; McAllister, K.; Manrai, A.; Patel, C.; Hall, M. What about the Environment? Leveraging Multi-Omic Datasets to Characterize the Environment's Role in Human Health. Pac. Symp. Biocomput. Pac. Symp. Biocomput. 2021, $26,309$. [PubMed]

14. Lloyd, R.E.; Tamhankar, M.; Lernmark, Å. Enteroviruses and Type 1 Diabetes: Multiple Mechanisms and Factors? Annu. Rev. Med. 2021, 73. [CrossRef] [PubMed]

15. Stanek, K.R.; Noser, A.E.; Patton, S.R.; Clements, M.A.; Youngkin, E.M.; Majidi, S. Stressful Life Events, Parental Psychosocial Factors, and Glycemic Management in School-Aged Children during the 1 Year Follow-up of New-Onset Type 1 Diabetes. Pediatric Diabetes 2020, 21, 673-680. [CrossRef]

16. Monzon, A.D.; Marker, A.M.; Noser, A.E.; Clements, M.A.; Patton, S.R. Associations Between Objective Sleep Behaviors and Blood Glucose Variability in Young Children With Type 1 Diabetes. Ann. Behav. Med. 2020, 55, 144-154. [CrossRef] [PubMed]

17. McConville, A.; Noser, A.E.; Nelson, E.L.; Clements, M.A.; Majidi, S.; Patton, S.R. Depression as a Predictor of Hypoglycemia Worry in Parents of Youth with Recent-Onset Type 1 Diabetes. Pediatric Diabetes 2020, 21, 909-916. [CrossRef]

18. Case, H.; Williams, D.D.; Majidi, S.; Ferro, D.; Clements, M.A.; Patton, S.R. Longitudinal Associations between Family Conflict, Parent Engagement, and Metabolic Control in Children with Recent-Onset Type 1 Diabetes. BMJ Open Diabetes Res. Care 2021, 9, e002461. [CrossRef] [PubMed]

19. Ward, M.J.; Marsolo, K.A.; Froehle, C.M. Applications of Business Analytics in Healthcare. Bus. Horiz. 2014, 57, 571-582. [CrossRef]

20. Rewers, A.; Chase, H.P.; Mackenzie, T.; Walravens, P.; Roback, M.; Rewers, M.; Hamman, R.F.; Klingensmith, G. Predictors of Acute Complications in Children With Type 1 Diabetes. JAMA 2002, 287, 2511-2518. [CrossRef]

21. Quick, C.; Anugu, P.; Musani, S.; Weiss, S.T.; Burchard, E.G.; White, M.J.; Keys, K.L.; Cucca, F.; Sidore, C.; Boehnke, M.; et al. Sequencing and Imputation in GWAS: Cost-effective Strategies to Increase Power and Genomic Coverage across Diverse Populations. Genet. Epidemiol. 2020, 44, 537-549. [CrossRef]

22. Diao, J.A.; Kohane, I.S.; Manrai, A.K. Biomedical Informatics and Machine Learning for Clinical Genomics. Hum. Mol. Genet. 2018, 27, R29-R34. [CrossRef]

23. Kamies, R.; Martinez-Jimenez, C.P. Advances of Single-Cell Genomics and Epigenomics in Human Disease: Where Are We Now? Mamm. Genome 2020, 31, 170-180. [CrossRef] [PubMed]

24. Zurawek, M.; Fichna, M.; Fichna, P.; Czainska, M.; Rozwadowska, N. Upregulation of FOXO3 in New-Onset Type 1 Diabetes Mellitus. J. Immunol. Res. 2020, 2020, 4-7. [CrossRef]

25. Martens, G.A.; Stangé, G.; Piemonti, L.; Anckaert, J.; Ling, Z.; Pipeleers, D.G.; Gorus, F.K.; Mestdagh, P.; de Smet, D.; Vandesompele, J.; et al. The MicroRNA Landscape of Acute Beta Cell Destruction in Type 1 Diabetic Recipients of Intraportal Islet Grafts. Cells 2021, 10, 1693. [CrossRef]

26. Ahmed, S.; Cerosaletti, K.; James, E.; Long, S.A.; Mannering, S.; Speake, C.; Nakayama, M.; Tree, T.; Roep, B.O.; Herold, K.C.; et al. Standardizing T-Cell Biomarkers in Type 1 Diabetes: Challenges and Recent Advances. Diabetes 2019, 68, 1366-1379. [CrossRef] [PubMed]

27. Hanna, S.J.; Tatovic, D.; Thayer, T.C.; Dayan, C.M. Insights From Single Cell RNA Sequencing Into the Immunology of Type 1 Diabetes-Cell Phenotypes and Antigen Specificity. Front. Immunol. 2021, 12, 751701. [CrossRef] [PubMed]

28. Hanna, S.J.; Powell, W.E.; Long, A.E.; Robinson, E.J.S.; Davies, J.; Megson, C.; Howell, A.; Jones, T.J.; Ladell, K.; Price, D.A.; et al. Slow Progressors to Type 1 Diabetes Lose Islet Autoantibodies over Time, Have Few Islet Antigen-Specific CD8+ T Cells and Exhibit a Distinct CD95hi B Cell Phenotype. Diabetologia 2020, 63, 1174-1185. [CrossRef] [PubMed]

29. Zhang, L.; Wu, H.; Zhao, M.; Lu, Q. Identifying the Differentially Expressed MicroRNAs in Autoimmunity: A Systemic Review and Meta-Analysis. Autoimmunity 2020, 53, 122-136. [CrossRef]

30. Kraus, A.U.; Penna-Martinez, M.; Shoghi, F.; Meyer, G.; Badenhoop, K. Monocytic Cytokines in Autoimmune Polyglandular Syndrome Type 2 Are Modulated by Vitamin D and HLA-DQ. Front. Immunol. 2020, 11, 583709. [CrossRef]

31. Colli, M.L.; Hill, J.L.E.; Marroquí, L.; Chaffey, J.; dos Santos, R.S.; Leete, P.; Coomans de Brachène, A.; Paula, F.M.M.; op de Beeck, A.; Castela, A.; et al. PDL1 Is Expressed in the Islets of People with Type 1 Diabetes and Is Up-Regulated by Interferons- $\alpha$ and- $\gamma$ via IRF1 Induction. EBioMedicine 2018, 36, 367-375. [CrossRef] [PubMed]

32. Li, R.; Lee, J.; Kim, M.S.; Liu, V.; Moulik, M.; Li, H.; Yi, Q.; Xie, A.; Chen, W.; Yang, L.; et al. PD-L1-Driven Tolerance Protects Neurogenin3-Induced Islet Neogenesis to Reverse Established Type 1 Diabetes in NOD Mice. Diabetes 2015, 64, 529-540. [CrossRef] 
33. Alam, M.; Arunagiri, A.; Haataja, L.; Torres, M.; Larkin, D.; Kappler, J.; Jin, N.; Arvan, P. Predisposition to Proinsulin Misfolding as a Genetic Risk to Diet-Induced Diabetes. Diabetes 2021, 70, 2580-2594. [CrossRef]

34. Sun, J.; Cui, J.; He, Q.; Chen, Z.; Arvan, P.; Liu, M. Proinsulin Misfolding and Endoplasmic Reticulum Stress during the Development and Progression of Diabetes. Mol. Asp. Med. 2015, 42, 105-118. [CrossRef] [PubMed]

35. Liu, M.; Hodish, I.; Haataja, L.; Lara-Lemus, R.; Rajpal, G.; Wright, J.; Arvan, P. Proinsulin Misfolding and Diabetes: Mutant INS Gene-Induced Diabetes of Youth. Trends Endocrinol. Metab. TEM 2010, 21, 652-659. [CrossRef]

36. Safari-Alighiarloo, N.; Taghizadeh, M.; Mohammad Tabatabaei, S.; Namaki, S.; Rezaei-Tavirani, M. Identification of Common Key Genes and Pathways between Type 1 Diabetes and Multiple Sclerosis Using Transcriptome and Interactome Analysis. Endocrine 2020, 68, 81-92. [CrossRef] [PubMed]

37. Chen, S.-J.; Cheng, J.-L.; Lee, S.-A.; Wang, T.-Y.; Jang, J.-Y.; Chen, K.-C. Elucidate Multidimensionality of Type 1 Diabetes Mellitus Heterogeneity by Multifaceted Information. Sci. Rep. 2021, 11, 20965. [CrossRef]

38. Pushpakom, S.; Iorio, F.; Eyers, P.A.; Escott, K.J.; Hopper, S.; Wells, A.; Doig, A.; Guilliams, T.; Latimer, J.; McNamee, C.; et al. Drug Repurposing: Progress, Challenges and Recommendations. Nat. Rev. Drug Discov. 2019, 18, 41-58. [CrossRef] [PubMed]

39. Ashburner, M.; Ball, C.A.; Blake, J.A.; Botstein, D.; Butler, H.; Cherry, J.M.; Davis, A.P.; Dolinski, K.; Dwight, S.S.; Eppig, J.T.; et al. Gene Ontology: Tool for the Unification of Biology. The Gene Ontology Consortium. Nat. Genet. 2000, 25, 25-29. [CrossRef] [PubMed]

40. Baranzini, S.E.; Wang, L.; Himmelstein, D.S.; Santaniello, A.; Parvin, M. ICTNet2: Integrating Heterogeneous Biological Interactions to Understand Complex Traits. F1000Research 2015, 4, 485. [CrossRef]

41. Goh, K.I.; Cusick, M.E.; Valle, D.; Childs, B.; Vidal, M.; Barabási, A.L. The Human Disease Network. Proc. Natl. Acad. Sci. USA 2007, 104, 8685-8690. [CrossRef] [PubMed]

42. Vudattu, N.K.; Herold, K.C. Treatment of New Onset Type 1 Diabetes with Teplizumab: Successes and Pitfalls in Development. Expert Opin. Biol. Ther. 2014, 14, 377-385. [CrossRef]

43. Paul, S.; Ruiz-Manriquez, L.M.; Ledesma-Pacheco, S.J.; Benavides-Aguilar, J.A.; Torres-Copado, A.; Morales-Rodríguez, J.I.; de Donato, M.; Srivastava, A. Roles of MicroRNAs in Chronic Pediatric Diseases and Their Use as Potential Biomarkers: A Review. Arch. Biochem. Biophys. 2021, 699, 108763. [CrossRef] [PubMed]

44. Nieto, J.; Castillo, B.; Astudillo, M.; Tosur, M.; Balasubramanyam, A.; Pietropaolo, M.; Redondo, M.J. Islet Autoantibody Types Mark Differential Clinical Characteristics at Diagnosis of Pediatric Type 1 Diabetes. Pediatric Diabetes 2021, 22, 882-888. [CrossRef]

45. Long, A.E.; George, G.; Williams, C.L. Persistence of Islet Autoantibodies after Diagnosis in Type 1 Diabetes. Diabet. Med. A J. Br. Diabet. Assoc. 2021, 38, e14712. [CrossRef] [PubMed]

46. Dozio, E.; Massaccesi, L.; Romanelli, M.M.C. Glycation and Glycosylation in Cardiovascular Remodeling: Focus on Advanced Glycation End Products and O-Linked Glycosylations as Glucose-Related Pathogenetic Factors and Disease Markers. J. Clin. Med. 2021, 10, 4792. [CrossRef]

47. Bent, B.; Cho, P.J.; Henriquez, M.; Wittmann, A.; Thacker, C.; Feinglos, M.; Crowley, M.J.; Dunn, J.P. Engineering Digital Biomarkers of Interstitial Glucose from Noninvasive Smartwatches. npj Digit. Med. 2021, 4, 89. [CrossRef]

48. Márquez, A.; Martín, J. Genetic Overlap between Type 1 Diabetes and Other Autoimmune Diseases. Semin. Immunopathol. 2021. [CrossRef]

49. Shepard, J.G.; Airee, A.; Dake, A.W.; McFarland, M.S.; Vora, A. Limitations of A1c Interpretation. South. Med. J. 2015, 108, 724-729. [CrossRef]

50. Oliveira, R.V.; Bernardo, T.; Martins, S.; Sequeira, A. Monogenic Diabetes: A New Pathogenic Variant of HNF1A Gene. BMJ Case Rep. 2021, 14. [CrossRef]

51. Zhang, M.; Luo, H.; Xi, Z.; Rogaeva, E. Drug Repositioning for Diabetes Based on “omics” Data Mining. PLoS ONE 2015, 10, e0126082. [CrossRef]

52. Bhattamisra, S.K.; Shin, L.Y.; Saad, H.I.B.M.; Rao, V.; Candasamy, M.; Pandey, M.; Choudhury, H. Interlink Between Insulin Resistance and Neurodegeneration with an Update on Current Therapeutic Approaches. CNS Neurol. Disord. Drug Targets 2020, 19, 174-183. [CrossRef] [PubMed]

53. Nyaga, D.M.; Vickers, M.H.; Jefferies, C.; Fadason, T.; O'Sullivan, J.M. Untangling the Genetic Link between Type 1 and Type 2 Diabetes Using Functional Genomics. Sci. Rep. 2021, 11, 13871. [CrossRef]

54. Nyaga, D.M.; Vickers, M.H.; Jefferies, C.; Perry, J.K.; O'sullivan, J.M. The Genetic Architecture of Type 1 Diabetes Mellitus. Mol. Cell. Endocrinol. 2018, 477, 70-80. [CrossRef] [PubMed]

55. Robertson, C.C.; Rich, S.S. Genetics of Type 1 Diabetes. Curr. Opin. Genet. Dev. 2018, 50, 7-16. [CrossRef]

56. Soofi, A.; Taghizadeh, M.; Tabatabaei, S.M.; Rezaei Tavirani, M.; Shakib, H.; Namaki, S.; Safari Alighiarloo, N. Centrality Analysis of Protein-Protein Interaction Networks and Molecular Docking Prioritize Potential Drug-Targets in Type 1 Diabetes. Iran. J. Pharm. Res. IJPR 2020, 19, 121-134. [CrossRef]

57. Perkins, B.A.; Sherr, J.L.; Mathieu, C. Type 1 Diabetes Glycemic Management: Insulin Therapy, Glucose Monitoring, and Automation. Science 2021, 373, 522-527. [CrossRef] [PubMed]

58. Morton, S.; Li, R.; Dibbo, S.; Prioleau, T. Data-Driven Insights on Behavioral Factors That Affect Diabetes Management. Proc. Annu. Int. Conf. IEEE Eng. Med. Biol. Soc. EMBS 2020, 5557-5562. [CrossRef]

59. Yoo, J.H.; Kim, J.H. Time in Range from Continuous Glucose Monitoring: A Novel Metric for Glycemic Control. Diabetes Metab. J. 2020, 44, 828-839. [CrossRef] 
60. Davis, S.; MacKay, L. Moving Beyond the Rhetoric of Shared Decision-Making: Designing Personal Health Record Technology With Young Adults With Type 1 Diabetes. Can. J. Diabetes 2020, 44, 434-441. [CrossRef]

61. Amed, S.; Nuernberger, K.; McCrea, P.; Reimer, K.; Krueger, H.; Aydede, S.K.; Ayers, D.; Collet, J.-P. Adherence to Clinical Practice Guidelines in the Management of Children, Youth, and Young Adults with Type 1 Diabetes-A Prospective Population Cohort Study. J. Pediatrics 2013, 163, 543-548. [CrossRef] [PubMed]

62. Rickels, M.R.; Evans-Molina, C.; Bahnson, H.T.; Ylescupidez, A.; Nadeau, K.J.; Hao, W.; Clements, M.A.; Sherr, J.L.; Pratley, R.E.; Hannon, T.S.; et al. High Residual C-Peptide Likely Contributes to Glycemic Control in Type 1 Diabetes. J. Clin. Investig. 2020, 130, 1850-1862. [CrossRef] [PubMed]

63. Gui, H.; Zheng, R.; Ma, C.; Fan, H.; Xu, L. An Architecture for Healthcare Big Datamanagement and Analysis. In Proceedings of the Lecture Notes in Computer Science (Including Subseries Lecture Notes in Artificial Intelligence and Lecture Notes in Bioinformatics), Shanghai, China, 5-7 November 2016; Springer: Berlin/Heidelberg, Germany, 2016; Volume 10038 LNCS, pp. 154-160.

64. Manrai, A.K.; Patel, C.J.; Ioannidis, J.P.A. In the Era of Precision Medicine and Big Data, Who Is Normal? JAMA 2018, $319,1981$. [CrossRef] [PubMed]

65. Belle, A.; Thiagarajan, R.; Soroushmehr, S.M.R.; Navidi, F.; Beard, D.A.; Najarian, K. Big Data Analytics in Healthcare. BioMed Res. Int. 2015, 2015, 3. [CrossRef] [PubMed]

66. Bradley, P.S. Implications of Big Data Analytics on Population Health Management. Big Data 2013, 1, 152-159. [CrossRef]

67. Clements, M.A.; Staggs, V.S. A Mobile App for Synchronizing Glucometer Data: Impact on Adherence and Glycemic Control among Youths with Type 1 Diabetes in Routine Care. J. Diabetes Sci. Technol. 2017, 11, 461-467. [CrossRef]

68. Aghanoori, M.R.; Smith, D.R.; Shariati-Ievari, S.; Ajisebutu, A.; Nguyen, A.; Desmond, F.; Jesus, C.H.A.; Zhou, X.; Calcutt, N.A.; Aliani, M.; et al. Insulin-like Growth Factor-1 Activates AMPK to Augment Mitochondrial Function and Correct Neuronal Metabolism in Sensory Neurons in Type 1 Diabetes. Mol. Metab. 2019, 20, 149-165. [CrossRef]

69. Peravali, R.; Gunnels, L.; Alleboina, S.; Gerling, I.C.; Dokun, A.O. Type 1 Diabetes Alters Ischemia-Induced Gene Expression. J. Clin. Transl. Endocrinol. 2019, 15, 19-24. [CrossRef]

70. van Zuydam, N.R.; Stiby, A.; Abdalla, M.; Austin, E.; Dahlström, E.H.; McLachlan, S.; Vlachopoulou, E.; Ahlqvist, E.; di Liao, C.; Sandholm, N.; et al. Genome-Wide Association Study of Peripheral Artery Disease. Circ. Genom. Precis. Med. 2021, 14. [CrossRef]

71. Dennis, K.K.; Auerbach, S.S.; Balshaw, D.M.; Cui, Y.; Fallin, M.D.; Smith, M.T.; Spira, A.; Sumner, S.; Miller, G.W. The Importance of the Biological Impact of Exposure to the Concept of the Exposome. Environ. Health Perspect. 2016, 124, 1504-1510. [CrossRef] [PubMed]

72. Rahaman, M.S.; Rahman, M.M.; Mise, N.; Sikder, T.; Ichihara, G.; Uddin, M.K.; Kurasaki, M.; Ichihara, S. Environmental Arsenic Exposure and Its Contribution to Human Diseases, Toxicity Mechanism and Management. Environ. Pollut. 2021, 289 , 117940. [CrossRef] [PubMed]

73. D'Autréaux, B.; Toledano, M.B. ROS as Signalling Molecules: Mechanisms That Generate Specificity in ROS Homeostasis. Nat. Rev. Mol. Cell Biol. 2007, 8, 813-824. [CrossRef] [PubMed]

74. Catania, F.; Krohs, U.; Chittò, M.; Ferro, D.; Ferro, K.; Lepennetier, G.; Görtz, H.D.; Schreiber, R.S.; Kurtz, J.; Gadau, J. The Hologenome Concept: We Need to Incorporate Function. Theory Biosci. 2017, 136, 89-98. [CrossRef]

75. Abstracts for the T1D Exchange QI Collaborative (T1Dx-QI) Learning Session 2021. November 8-9, 2021. J. Diabetes 2021, $13,3-17$. [CrossRef] [PubMed]

76. American Diabetes Association. 2. Classification and Diagnosis of Diabetes: Standards of Medical Care in Diabetes-2021. Diabetes Care 2021, 44, S15-S33. [CrossRef] [PubMed] 